\title{
Letter to Editors \\ Fractal Relation of Medial Axis Length to the Water Body Area
}

\author{
B.S. DAYA SAGAR* \\ Department of Geoengineering, Centre for Remote Sensing and Information Systems, Andhra University, \\ Visakhapatnam - 530003, India
}

(Received 17 March 1999)

As it was demonstrated by Mandelbrot (1982), the power value is not 2 for non-standard shapes, fractals, the relation between the length of medial axis (Serra, 1982), $L$, and area, $A$, of surface water body is taken in the form of $L \sim A^{b}$, where, $b=d / 2$ is an exponent fitted to the data. The fractal relation between water body area, $A$, to the length of medial axis of water body is proposed. Through this fractal relation it is indicated that $L \sim A^{d / 2}$. More than 160 surface water bodies have been traced from satellite remote sensing data, covering the area between the geographical co-ordinates of $18^{\circ} 00^{\prime}$ to $18^{\circ} 30^{\prime}$ north latitudes and $83^{\circ} 15^{\prime}$ to $83^{\circ} 45^{\prime}$ east longitudes. These traced water bodies are digitised and converted the data into water body and no-water body regions. The lengths of medial axis and areal extents of 160 water bodies, in pixel units, have been computed. A graph is plotted between logarithm of area and logarithm of length of medial axis of 160 water bodies. The fractal dimension of medial axis length, $d$, is computed as $1.113 \pm 0.01$ for 160 water bodies. The data are well fitted as the power law $L \sim A^{0.556}$, which equals $d / 2 . b=d / 2$ value almost tallied with derived exponent power value, i.e., 0.556 . The value $2 b$ is almost equal to $1.113 \pm 0.01$ which is computed as fractal dimension of medial axis length. Strikingly this is close to the value of 1.136, the fractal dimension of the length of the main water course, which is hypothesised by Mandelbrot.

\section{References}

Mandelbrot, B.B. Fractal Geometry of Nature, Freeman \& Co., San Francisco, 1982, p. 468.

Serra, J. Mathematical Morphology and Image Analysis, Academic Press, New York, 1982, p. 610.

\footnotetext{
* Presently with Centre for Remote Imaging, Sensing, Processing (CRISP), Faculty of Science, National University of Singapore, Lower Kent Ridge Road, Singapore - 119260.
} 


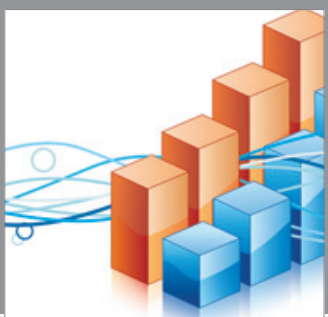

Advances in

Operations Research

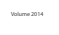

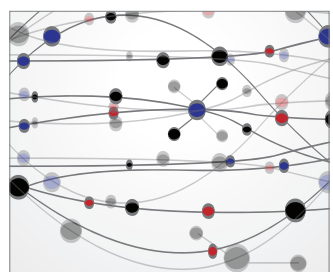

\section{The Scientific} World Journal
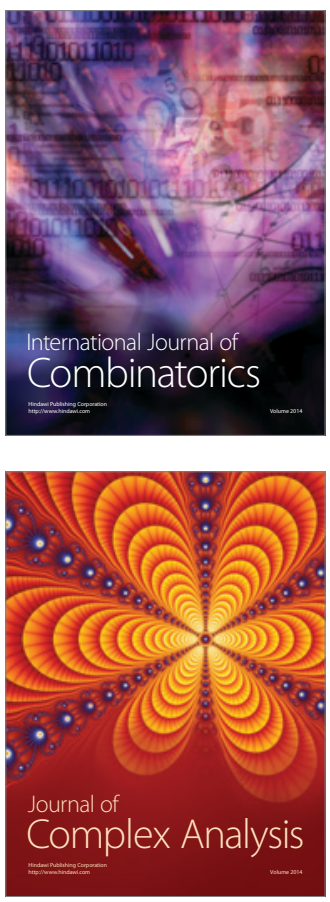

International Journal of

Mathematics and

Mathematical

Sciences
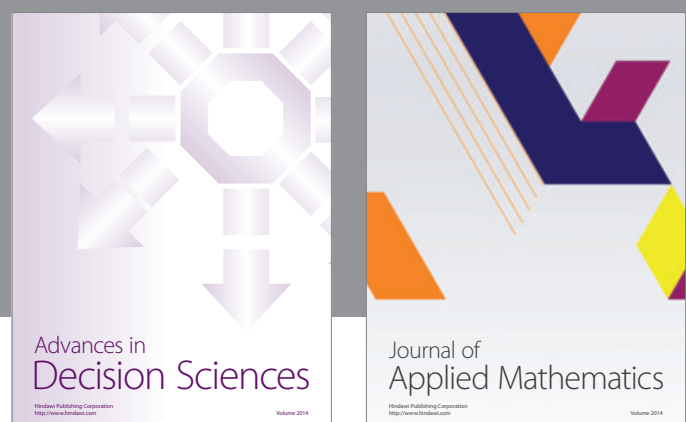

Journal of

Applied Mathematics
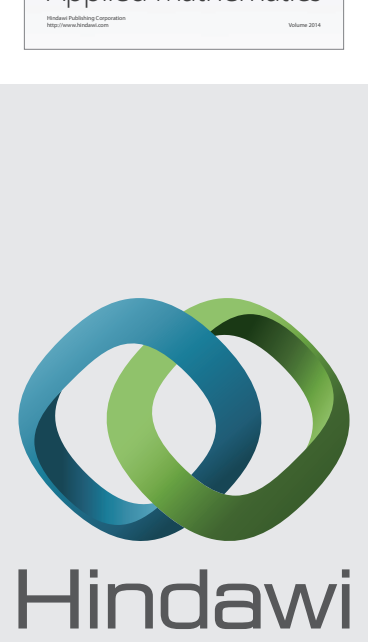

Submit your manuscripts at http://www.hindawi.com
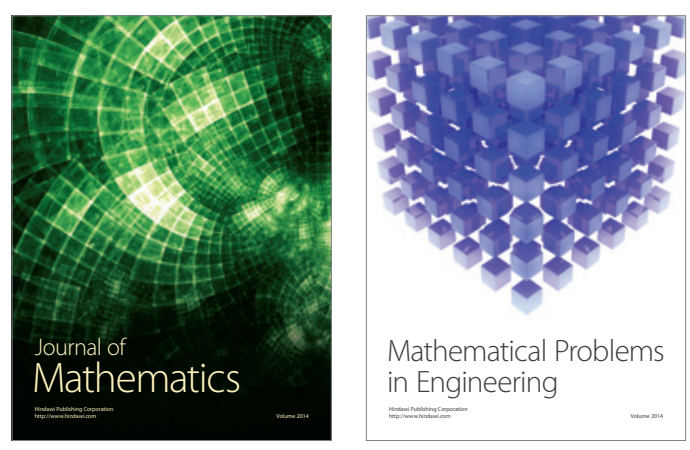

Mathematical Problems in Engineering
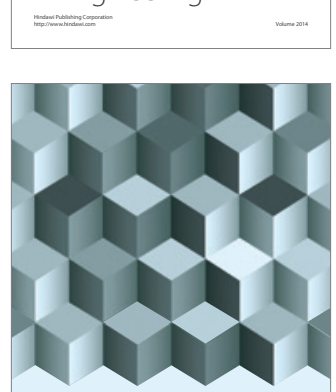

Journal of

Function Spaces
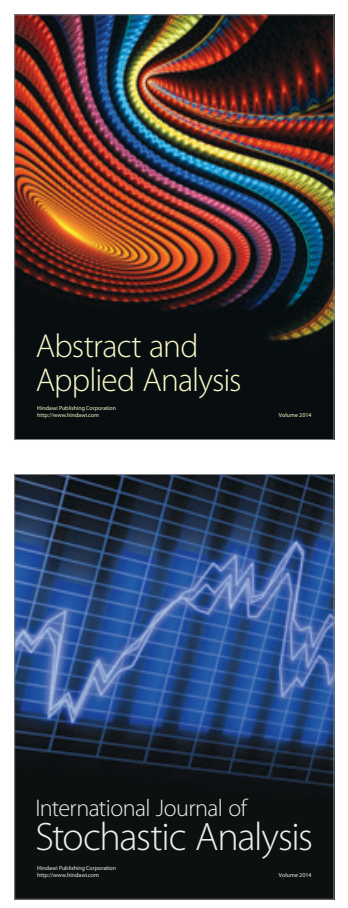

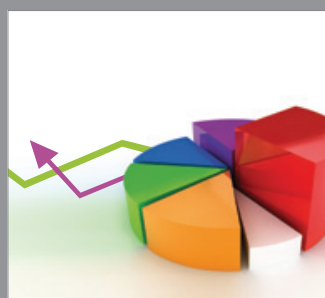

ournal of

Probability and Statistics

Promensencen
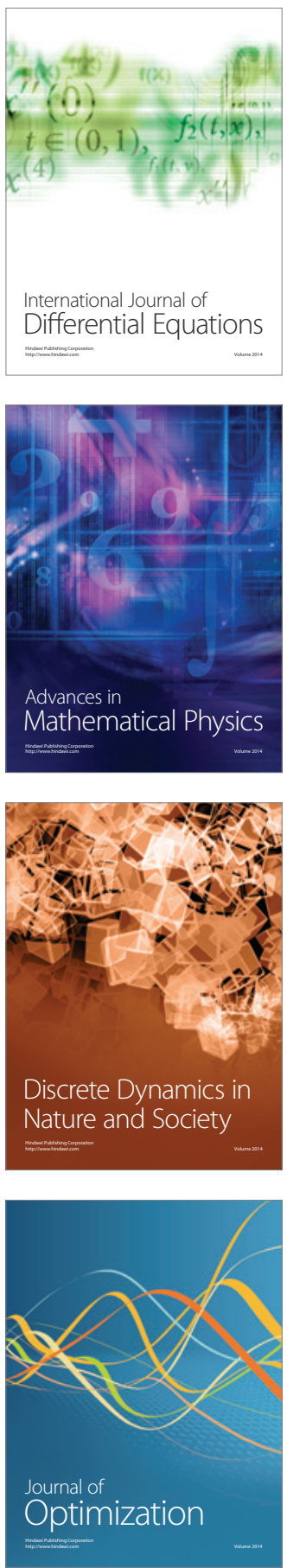